\title{
ARTÍCULO
}

\section{Los prejuicios no percibidos y el caso Sócrates: un ejemplo paradigmático*.}

\section{The hidden prejudices and the Socrates case: a paradigmatic example.}

\author{
Aurelio de Prada García \\ Universidad Rey Juan Carlos \\ http://orcid.org/0000-0002-5160-3325
}

Fecha de recepción 20/05/2021 | De aceptación: 11/10/2021 | De publicación: 23/12/2021

\section{RESUMEN.}

En un trabajo anterior defendimos que no se había prestado suficiente atención al procedimiento utilizado en el juicio contra Sócrates, sin que examináramos las causas de esa desatención. Ahora, tras analizarlas, llegamos a la conclusión de que ese procedimiento se habría malentendido completamente al haberse implementado un prejuicio no percibido. Habríamos extrapolado a ese procedimiento los presupuestos individualistas de los procedimientos vigentes hoy en día y, en consecuencia, habríamos estado sordos a lo que nos dice la tradición. Un ejemplo de sordera que podría ser muy útil para detectar otros casos semejantes de implementación de prejuicios no percibidos.

\section{PALABRAS CLAVE.}

Gadamer; prejuicios no percibidos; procedimiento judicial; Sócrates; sordera; tradición.

\section{ABSTRACT.}

In a previous work, we defended that the procedure used in the trial against Socrates had not received enough consideration, but we did not pay attention to the causes of it. Now, after analyzing those causes, we arrive at the conclusion that that procedure has been completely misunderstood due to the implementation of a hidden prejudice. We would have extrapolated the individualistic presumptions of our procedures to that procedure so that we would have been deaf to what tradition says to us. This example of deafness could be very useful in other to detect similar cases of implementation of hidden prejudices

\section{KEY WORDS.}

Deafness; Gadamer; hidden prejudices; Socrates; tradition; trial procedures.

\footnotetext{
- Una primera versión de este trabajo fue presentada al Congreso online MIGRACIÓN, ASILO Y DIVERSIDAD CULTURAL EN LA UNIÓN EUROPEA, celebrado los días 11 y 12 de mayo de 2021 en el marco del Proyecto Puente de Investigación de la Universidad Rey Juan Carlos "Inmigración y gestión de la diversidad cultural", del Grupo de investigación de alto rendimiento: INGESDICUL del que es IP la profesora María Cristina Hermida del Llano.
} 
"En consecuencia, no se trata en modo alguno de asegurarse a sí mismo contra la tradición que hace oír su voz desde el texto, sino, por el contrario, de mantener alejado todo lo que pueda dificultar el comprenderla desde la cosa misma. Son los prejuicios no percibidos los que con su dominio nos vuelven sordos hacia la cosa desde la que nos habla la tradición.”.

Gadamer, H. G.: Verdad y método.

Sumario: 1. Introducción: El caso Sócrates. 2. Sordos a la tradición. 3. Un prejuicio no percibido individualista. 4. A modo de conclusión. 5. Bibliografía utilizada.

\section{Introducción: El caso Sócrates.}

En un trabajo anterior ${ }^{1}$, defendimos que no se había tenido suficientemente en cuenta el procedimiento utilizado en el juicio contra Sócrates en el año 399 a.C., acusado de impiedad y corrupción de los jóvenes, y que ello había provocado una incomprensión completa de la actitud que adoptó tras el veredicto de culpabilidad.

Sin embargo, en ese trabajo no examinamos las causas de esa falta de atención a dicho procedimiento; cosa que ahora sí haremos hasta llegar a la conclusión de que se habría implementado un prejuicio no percibido en el sentido de Gadamer ("die undurchschauten Vorurteile"2). Prejuicio que, en "el caso Sócrates", nos habría impedido escuchar; nos habría hecho "sordos" a lo que la tradición, en "su sentido propio y diferente" 3 , nos dice.

En "el caso Sócrates" decimos y podría pensarse que no decimos bien pues, dado que en este trabajo analizaremos las causas por las que se ha malinterpretado el procedimiento utilizado en el juicio contra Sócrates y no ese juicio en concreto, cabría aducir que no procede usar la denominación "el caso Sócrates" y que deberíamos utilizar la de "el caso del procedimiento utilizado en el juicio contra

\footnotetext{
${ }^{1}$ PRADA, A. de: Tomando a Sócrates en serio: De la ciudadanía antigua a la ciudadanía glocal. Anales de la Cátedra Francisco Suárez, n. 54, Granada 2020, p. 53-70.

2 "Es sind die undurchschauten Vorurteile, deren Herrschaft uns gegen die in der Überlieferung sprechende Sache taub macht." GADAMER, H. G.; Wahrheit und Methode en Gesammelte Werke tomo 1, München, Mohr Siebeck, 1990, p. 274.

3 "Una conciencia verdaderamente histórica aporta siempre su propio presente, y lo hace viéndose tanto a sí misma como a lo históricamente otro en sus verdaderas relaciones. Por supuesto que ganar para sí un horizonte histórico requiere un intenso esfuerzo. Uno no se sustrae a las esperanzas y temores de lo que le es más próximo, y sale al encuentro de los testimonios del pasado desde esta determinación. Por eso es una tarea tan importante como constante impedir una asimilación precipitada del pasado con las propias expectativas de sentido. Sólo entonces se llega a escuchar la tradición tal como ella puede hacerse oír en su sentido propio y diferente.” GADAMER, H. G.; Verdad y método, Vol. I Sígueme, Salamanca, 1996, p. 335 y 336.
} 
Sócrates”. Ahora bien, la denominación “el caso Sócrates” resulta plenamente justificada no sólo por razones de economía de escritura, sino porque el "caso del procedimiento seguido en el juicio contra Sócrates" resultaría ser, en último término, "el caso Sócrates" a la vista de las siguientes consideraciones.

En primer lugar y como es bien sabido, al tratar de la figura y el pensamiento de Sócrates lo primero con lo que uno se encuentra es con la llamada "cuestión socrática"; esto es, con el hecho de que no disponemos de obra escrita por parte del propio Sócrates y de que los testimonios sobre él son en muchas ocasiones contradictorios ${ }^{4}$ y ello hasta el punto de haberse llegado a sostener la tesis de la imposibilidad de reconstruir su figura histórica y su auténtico pensamiento ${ }^{5}$. Con todo lo cual, bien podría concluirse utilizando el término "caso" en sentido no jurídico y denominando, en consecuencia, la “cuestión socrática" "el caso Sócrates".

Esta conclusión resulta, sin embargo, provisional y es que la denominación "el caso Sócrates" a la que acabamos de llegar, cobraría sentido jurídico pleno si se tiene en cuenta que hay acuerdo prácticamente unánime en que, de todas las circunstancias de la vida de Sócrates, es precisamente el juicio al que fue sometido en el año 399 a.C., la más relevante para analizar su figura y, -si es que así puede hablarse-, su pensamiento, así como su proyección futura. Buena prueba de ello sería tanto la ingente y casi inabarcable bibliografía al respecto, cuanto que, de ese proceso y de su resultado, se ha hecho depender

\footnotetext{
4 “Sócrates no escribió nada, ya que consideraba que su mensaje debía comunicarse a través de la palabra viva, a través del diálogo y de la oralidad dialéctica, como se ha dicho con precisión. Sus discípulos establecieron por escrito una serie de doctrinas que se le atribuyen. Estas doctrinas, sin embargo, a menudo no coinciden y, a veces, incluso se contradicen. Aristófanes caricaturiza a un Sócrates que, como hemos observado, no es el de la última madurez. En la mayor parte de sus diálogos Platón idealiza a Sócrates y lo convierte en portavoz de sus propias doctrinas, en consecuencia, resulta muy difícil determinar qué es lo que pertenece efectivamente a Sócrates y qué corresponde, en cambio, a planteamientos y reelaboraciones que formula Platón. Jenofonte en sus escritos socráticos presenta a un Sócrates a escala reducida, con rasgos que a veces rozan lo superficial (habría sido realmente imposible que los atenienses tuviesen motivos para condenar a muerte a un hombre como el Sócrates que nos describe Jenofonte). Aristóteles habla de Sócrates de forma ocasional; sin embargo, con frecuencia, se ha considerado que sus afirmaciones son las más objetivas. Con todo, Aristóteles no fue contemporáneo suyo. Pudo sin duda documentarse acerca de lo que nos refiere; pero le faltó el contacto directo con el personaje, contacto que en el caso de Sócrates resulta insustituible. Finalmente, los diversos socráticos, fundadores de las llamadas "escuelas socráticas menores", poco nos han dejado y este poco no sirve más que para iluminar un aspecto parcial de Sócrates.” REALE, G. y ANTISERI, D.; Historia del pensamiento filosófico y científico. Tomo I Antigüedad y Edad Media, Herder, Barcelona; 1995, p. 85 y 86.
}

${ }^{5}$ REALE, G. y ANTISERI, D.; Historia del pensamiento filosófico y científico, cit., p. 86. 
tanto la formulación misma de la filosofía socrática ${ }^{6}$, como la de la platónica $^{7}$ y, con ésta última, la de toda la filosofía europea posterior considerada por algunos bien como meras notas a pie de página de la obra de Platón ${ }^{8}$, bien como escrita en clave exclusivamente platónica ${ }^{9}$. Con todo lo cual, efectivamente, bien podría concluirse definitivamente que la "cuestión socrática" equivale a "el caso Sócrates" en el sentido jurídico del término "caso".

Un sentido jurídico aún más pleno, toda vez que, como ya hemos anticipado y trataremos de demostrar aquí, el punto central en "el caso Sócrates" sería precisamente el del procedimiento empleado en él. Un procedimiento radicalmente diferente de los nuestros y, por tanto, expresión de una mentalidad jurídica, de un horizonte de praxis diferente desde el que habría que entender la actitud adoptada por Sócrates. Cosa que, sin embargo, no habríamos hecho ya que no sólo se ignora habitualmente dicho procedimiento, sino que, en las escasas ocasiones en las que sí se considera, apenas si se ponen de relieve las diferencias con el nuestro, -si es que no se tergiversan-, y todo ello, como trataremos de demostrar aquí, implementando un prejuicio no percibido que nos hace sordos a lo que la tradición nos dice.

\section{Sordos a la tradición}

Y en efecto, hasta donde llega nuestro conocimiento, no hay referencias a tal procedimiento en la inmensa mayoría de los manuales de filosofía del derecho accesibles al lector castellano ${ }^{10}$, en los de historia de

\footnotetext{
6 "Sócrates, la principal figura filosófica de este siglo, aunque no se preocupó demasiado del derecho ni de la retórica, sin embargo, tuvo que hacer frente a un proceso criminal, realizó su propia defensa ante el tribunal (discurso que conservamos gracias a Jenofonte y a Platón) y, finalmente, llegó a perder su vida por una sentencia condenatoria de éste. Incluso el éxito de su filosofía quizás dependió en gran medida de aquella discutible o desafortunada decisión jurídica." LÓPEZ HERNÁNDEZ, J.; Historia de la filosofía del derecho clásica y moderna. Valencia, Tirant lo Blanch, 1998 p. 43.

7 "Si Sócrates no hubiera hecho su defensa con ese su estilo tan personal, el jurado ateniense no le habría condenado a muerte, y esa muerte no hubiera suscitado el escándalo y las apologías de sus discípulos, y acaso entonces Platón no lo habría tomado como protagonista de sus Diálogos, y entonces la historia de la filosofía griega y occidental habría sido distinta." GARCÍA GUAL, C.; "Acerca de El proceso de Sócrates de Gregorio Luri”, en LURI MEDRANO, G.; El proceso de Sócrates., Madrid, Trotta, 1998, p. 9.

${ }^{8}$ WHITEHEAD, A.N.; Process and Reality, New York, p. 63. Cit., por LLEDÓ E.; "Introducción general” en Platón: Diálogos I, Madrid, Gredos, 1981, p. 30. También PARDO, J.L.; La regla del juego. Barcelona, Galaxia Gutenberg, 2004, p.13: "Hablando en general, los libros de filosofía comienzan todos ellos el mismo día: al día siguiente de la muerte de Sócrates."

9 “Tanto es así que el filósofo inglés Alfred North Whitehead llegó a afirmar que "la manera más segura de describir el conjunto de la tradición filosófica europea es presentarla como una serie de acotaciones a Platón" (Proceso y realidad) o, más recientemente, el furibundo antiplatónico, Michel Onfray, para quien "la escritura de la historia de la filosofía es platónica. Ampliemos el marco: la historiografía dominante en el Occidente liberal es platónica" (Las sabidurías de la antigüedad-contrahistoria de la filosofía).” DAL MASCHIO, E. A.; Platón, Barcelona, Batiscafo, 2015, p. 10.

${ }^{10}$ No hay referencia alguna a la mecánica procesal del juicio en el que fue condenado en ninguna de las principales historias de la filosofía del derecho accesibles al lector castellano como las de FASSÓ G.; Historia de la Filosofía del Derecho. Vol. I, Madrid, Pirámide, 1966; RODRÍGUEZ PANIAGUA, J.M.; Historia del pensamiento jurídico. Vol. I De Heráclito a la Revolución Francesa. Servicio Publicaciones de la Facultad de Derecho, Madrid, Universidad Complutense, 1996; TRUYOL y SERRA, A.; Historia de la Filosofía del Derecho y del Estado, Vol. 1. Madrid, Alianza Universidad, 1982 o LÓPEZ HERNÁNDEZ, J.; Historia de la Filosofía del Derecho clásica y moderna,
} 
la ética ${ }^{11}$, en los de historia de la filosofía política ${ }^{12}$, en los de historia de la filosofía en general ${ }^{13}$, de la filosofía griega ${ }^{14}$, en algunas de las monografías dedicadas a Sócrates ${ }^{15}$ e, incluso en algunos estudios dedicados específicamente al proceso a que fue sometido ${ }^{16}$.

No parece necesario insistir en las consecuencias que se derivan de semejante ausencia de toda referencia al procedimiento utilizado en el caso Sócrates. Y es que, al no tenerlo siquiera en consideración, se obvian las posibles diferencias entre ese procedimiento y los nuestros, dando por supuesto, en consecuencia, que no las habría. Por decirlo en los términos de Gadamer: no escuchamos mayoritariamente lo que la tradición nos dice respecto al caso Sócrates porque, de forma no deliberada, la reducimos al silencio, concluyendo, pues, implícitamente, que nada tiene que decirnos diferente de lo que dice nuestra mentalidad jurídica, nuestro horizonte de praxis.

Ahora bien, aunque ciertamente mayoritaria, no es esa la única manera de desoír lo que la tradición nos dice en relación con el caso Sócrates y es que, frente a ese modo "implícito” de apropiación de ese caso, -por así decirlo-, habría un modo explícito como puede seguirse de la cita siguiente, muy reciente por lo demás, del año 2016:

cit. La única, hasta donde llega nuestro conocimiento, que toma en consideración tal procedimiento es la de VERDROSS, A.; La filosofía del derecho del mundo occidental. México, UNAM, 1983, p. 49 y 50.

${ }^{11}$ Tampoco MACINTYRE, A.; Historia de la Ética. Barcelona, Paidós Studio, 1988 y García Gual, C: "Los Sofistas y Sócrates" en VVAA; Historia de la ética., Barcelona, Crítica, 1987 incluyen, en sus exposiciones de Sócrates, referencia alguna al procedimiento seguido en el juicio contra él.

12 Una excepción, SABINE, G.H.; Historia de la Teoría Política. México, FCE 1972 p. 19 y 20.

${ }^{13}$ No hay referencia alguna en, por ejemplo, COOPER, D. E.; Filosofías del Mundo. Madrid, Cátedra, 2007 ni en STÖRIG, H. J.; Historia universal de la Filosofía. Madrid Tecnos, 1995. Por el contrario, sí aparecen referencias en ABBAGNANO, N.; Historia de la Filosofía. Vol. I, Barcelona, Montaner y Simón, 1973, p. 63 y RUSSELL, B.; Historia de la Filosofía. Madrid, RBA, 2009 p. 129 y 130.

14 Tampoco hay referencias en SEVERINO, E.; La filosofía antigua. Barcelona, Ariel, 1986 ni en GUTHRIE E, W.K.C.; Historia de la Filosofía Griega. Vol. III., Madrid, Gredos, 1988.

${ }^{15}$ No hay referencia alguna, por ejemplo, en RIVAS PALÁ, P.; Justicia, Comunidad, Obediencia. El pensamiento de Sócrates ante la Ley. Pamplona, Eunsa, 1996.

${ }^{16}$ Así, por citar un estudio reciente, no hay descripción general alguna del procedimiento utilizado en el juicio contra Sócrates en HERMAN HANSEN, M.; El juicio de Sócrates desde el punto de vista ateniense. Universitas Philosophica 67, año 33, Bogotá, Colombia, juliodiciembre 2016, pp. 17-52., doi:10.11144/Javeriana.uph33-67.jsv. Por el contrario, sí que aparece descrito en STONE, I. F. El juicio de Sócrates. Madrid, Mondadori, 1988, si bien se limita a señalar que en "En un juicio criminal ateniense, el jurado votaba dos veces. La primera votación decidía sobre la condena o la absolución. Entonces, si el veredicto era la condena, se votaba otra vez sobre la pena." p. 195 y, más adelante, "Bajo la ley ateniense, el jurado no podía decidir la pena por su cuenta. Tenía que elegir entre la pena propuesta por la acusación y la propuesta por la defensa”. p. 200. Esto es, sin hacer consideración alguna sobre las características diferenciales de ese procedimiento en relación con los nuestros. 
“... a la edad de 70 años, Sócrates fue acusado de impiedad (es decir, de no honrar a los dioses como se debe), de promover esa impiedad entre los jóvenes y, por tanto, de corromperlos. Fue juzgado, encontrado culpable y condenado a muerte." 17

Y, en efecto, dejando al margen los cargos contra él, la última frase del texto es buena muestra de esa apropiación explícita, ya que los términos en los que se resume dicho juicio:

"Fue juzgado, encontrado culpable y condenado a muerte.",

serían perfectamente aplicables a un juicio celebrado en un ordenamiento jurídico contemporáneo en el que estuviera vigente la pena de muerte, cuando las características del procedimiento seguido en el caso Sócrates no se corresponden en absoluto con las de nuestros sistemas jurídicos. Por decirlo de nuevo en los términos de Gadamer: en este caso no se reduce al silencio a la tradición, sino que, -una vez más, de forma no percibida-, se le hace decir lo que dice nuestra propia mentalidad jurídica, nuestro horizonte de praxis.

A todo esto, bien podría decirse que estamos yendo muy deprisa y que estamos derivando conclusiones de desatención a lo que nos dice la tradición y, por tanto, de tergiversarla, sin que hayamos hecho la menor mención a las diferencias entre los respectivos procedimientos: el del caso Sócrates y los nuestros. Y ciertamente hasta aquí no hemos hecho mención alguna a estas diferencias que, desde luego, son más que notables, tal y como se desprende de la descripción del procedimiento seguido en el caso Sócrates que -a partir de los pocos textos que, hasta donde sabemos, se refieren a él ${ }^{18}$-, figura a continuación.

Ante cualquier peligro potencial o real para la pólis, cualquier ciudadano podía presentar una denuncia ante un magistrado si bien, para evitar que se pudiera acusar sin fundamento, tenía que realizar un depósito judicial de modo que, si era incapaz de conseguir un mínimo de un quinto de los votos emitidos, se le castigaba con una multa de mil dracmas e, incluso, podía llegar a ser merecedor de la atimia, la pérdida de ciudadanía.

\footnotetext{
${ }^{17}$ SANCÉN RODRÍGUEZ, J. y ANCHONDO PAVÓN, S.; Filosofía. Ciudad de México, SEP, 2016, p. 85.

${ }^{18}$ Para esta descripción del procedimiento seguido en el juicio contra Sócrates nos hemos servido de LURI MEDRANO, G.; El proceso de Sócrates. cit, pp. 19-21: BRICKHOUSE, TH. C. y SMITH, N. D.; Socrates on Trial. Oxford, Clarendon,1990, p. 24-26; SABINE. H.; Historia de la Teoría Política, cit. pp. 19 y 20; CARTLEDGE, P.; Ancient Greek Political Thought in Practice. Cambridge, Cambridge University Press, 2009, p. 89; así como de algunas notas de la traducción de CALONGE, J. de la Apología de Sócrates en PLATÓN; Diálogos I, Madrid, Gredos, 1981.
} 
Si la denuncia versaba sobre una cuestión relacionada con la religión, el tribunal estaba presidido por el arconte rey que era también el encargado de realizar una audiencia preliminar con los acusados y de llevar a cabo la instrucción previa. Tras señalarse el día del juicio, se elegían quinientos jueces por sorteo entre una lista de seis mil ciudadanos designada anualmente por los demos. Todos los ciudadanos mayores de 30 años podían ser elegidos para el desempeño de esta obligación, pagándose las dietas correspondientes a los elegidos.

Para evitar que las partes pudieran conocer de antemano el nombre de los jueces, el tribunal se constituía con grandes precauciones celebrándose el sorteo al amanecer del mismo día en que tendría lugar el juicio. Los jueces se sentaban en largas hileras de bancos cubiertos por esteras, teniendo enfrente dos estrados vecinos, con los acusadores y el acusado. Detrás de éstos se colocaban los espectadores. La sesión se iniciaba con una purificación y una plegaria entonada por el heraldo. Para preservar la independencia del jurado los debates no se interrumpían y el juicio debía concluir en el mismo día, para lo cual se limitaba el tiempo de intervención de las partes que estaban obligadas a defender personalmente sus posiciones.

No existía la deliberación entre los jueces; no podían consultarse, por tanto, unos a otros. Cada cual actuaba de acuerdo con un juramento cuya fórmula ha llegado hasta nosotros y cuyo texto era el siguiente:

"Emitiré mi voto de acuerdo con las leyes y los acuerdos del pueblo de Atenas y del Consejo de los Quinientos, y en los casos para los que no hubiera ley, de acuerdo con mi más justa convicción. No aceptaré regalos en mi cargo de juez ni yo mismo, ni otro u otros lo aceptarán para mí y con mi conocimiento, y ello de ningún modo o manera. Oiré igualmente al acusador y al acusado y pronunciaré mi juicio sólo sobre el asunto a debate. Así lo juro por Zeus, Apolo y Démeter, y conjuro las desgracias sobre mí y sobre mi casa si en algo falto a lo jurado y mucha ventura si lo cumplo." 19 .

En los casos donde no existía una pena previamente establecida para los delitos de los que se acusaba, esto es, en casos de agôn timetôs era el acusador, quien proponía la pena (tímesis), incluso la de muerte como en el caso de Sócrates. Si el acusado era declarado culpable, se le concedía la palabra para que expresara libremente qué pena le parecía merecer (antitímesís), tras lo cual se procedía a una segunda votación que decidía entre las dos penas propuestas. La decisión tenía valor de cosa juzgada porque no había sistema de apelación.

19 KNAUSS, B.; LA POLIS. Individuo y estado en la Grecia Antigua. Madrid, Aguilar, 1979, p. 136. 
A la vista de esta descripción no parece necesario insistir en las diferencias entre el procedimiento que acabamos de describir y nuestros procedimientos. Y es que una mecánica procesal en la que las partes actúan por sí mismas y, en su caso, proponen el castigo que consideran pertinente; en la que el juradotribunal, compuesto por simples ciudadanos, se limita a escuchar y a pronunciarse sin deliberación entre ellos sobre la culpabilidad, y, en su caso, sobre las penas que se le proponen y todo en un solo día y de modo inapelable resulta no solo chocante sino radicalmente contrario a nuestra mentalidad jurídica, a nuestro horizonte de praxis.

En efecto y sin ir más lejos, en nuestra mentalidad resultan imprescindibles los llamados operadores jurídicos o juristas prácticos: abogados defensores, fiscales, procuradores... Asimismo, y por mucho que la institución del jurado vaya ganando protagonismo, resulta impensable para nuestra mentalidad jurídica que pueda llegarse a una decisión sin deliberación previa entre sus componentes.

Más aún, el procedimiento utilizado en el caso Sócrates choca también con aspectos básicos de nuestro sentimiento de justicia dentro del cual se incluyen, como componentes fundamentales, tanto el principio de nullum crimen, nulla poena sine lege previa, -esto es, ningún crimen, ninguna pena sin ley previa-, cuanto el reconocimiento de la existencia de circunstancias agravantes, atenuantes y eximentes, cuanto, en fin, el de la posibilidad de error judicial con el establecimiento de los pertinentes recursos.

“A la vista de esta descripción no parece necesario insistir en las diferencias entre el procedimiento que acabamos de describir y nuestros procedimientos" decíamos más arriba y decíamos mal, pues, en los textos de los que nos hemos servido para la anterior descripción, no se ponen de manifiesto esas diferencias evidentes que acabamos de señalar sucintamente, por lo demás. Con lo cual, y por decirlo de nuevo con Gadamer, se oye, de forma muy minoritaria, lo que dice la tradición, pero sin que se la escuche realmente pues lo que se oye no lleva a considerarla diferente a nuestra mentalidad jurídica, a nuestro horizonte de praxis como debería ser el caso.

Pero, una vez más, podría decirse que concluimos con demasiada rapidez, pues, si bien en esos textos no hay una comparación entre ambos procedimientos como la que acabamos de realizar, sí que hay comentarios puntuales como los dos siguientes: 
"El sistema judicial ateniense era bastante rudimentario y podía dar lugar a grandes injusticias." 20 ,

$\mathrm{y}$

"Estos ciudadanos eran jueces y jurados, porque el tribunal ateniense carecía del aparato que acompaña a un sistema jurídico técnicamente desarrollado" 21.

Ciertamente cabría pensar que estos dos comentarios vienen a demostrar que sí se habría escuchado lo que dice la tradición y ello hasta el punto de establecer comparaciones con nuestro horizonte de praxis, extrayendo las conclusiones oportunas. Conclusiones que se concretarían en la afirmación general de que no habría diferencias sustanciales entre el procedimiento utilizado en el caso Sócrates y los nuestros. Ambos estarían dentro de la misma mentalidad jurídica, -la misma tradición, por así decirlo-, con la única diferencia de que los nuestros estarían en un estadio más avanzado, más desarrollado técnicamente.

Ahora bien, dejando al margen lo minoritario de esta postura, esta conclusión choca con los corolarios que se siguen de la comparación entre los presupuestos de ambos procedimientos. Comparación que hace dudar con fundamento de que, efectivamente, estemos en un estadio más avanzado dentro de la misma tradición ya que, más bien, estaríamos en un estadio más retrasado, si es que no directamente en otra tradición cultural.

Y en efecto, haciendo abstracción, -si es que ello es posible-, del tema de la esclavitud, parece que esa tradición, presuntamente rudimentaria y poco desarrollada desde un punto de vista técnico jurídico, iría más allá que la nuestra en lo que se refiere a la capacidad política del ciudadano; a la aplicación del principio democrático de la igual capacidad de todos los ciudadanos ${ }^{22}$. Y es que, a diferencia de lo que ocurre en nuestro horizonte de praxis, la condición política de ciudadano no se reduce a la elección

\footnotetext{
${ }^{20}$ CALONGE, J.; Apología de Sócrates, cit. p. 144, nota 6.

${ }^{21}$ SABINE, G.H.; Historia de la Teoría Política, cit. p. 20.

${ }^{22}$ Por decirlo con las palabras que Platón pone en boca de Protágoras: "Todos los hombres creen que cualquiera participa de la justicia y de la virtud política en general.” PLATÓN; Protágoras, en Diálogos, I., cit. 323a, p. 528. He desarrollado este punto en PRADA, A. de; Soberanía popular, poder judicial y jurado en el sistema jurídico español: Algunas consideraciones. Revista de la Facultad de Derecho de la Universidad Complutense, n. 93, Madrid 2000, pp. 221-233
} 
periódica de representantes, sino que se define precisamente por la participación en la administración de justicia y en el gobierno ${ }^{23}$.

En otros términos, se considera que el ámbito más característico de ejercicio de la ciudadanía lo constituye no la capacidad normativa por medio de representantes, sino el de la formulación y aplicación simultánea del derecho en el momento de la impartición de la justicia de modo que la sentencia sería un acto político; más aún, el acto político por excelencia. Todo lo cual parece hacer perfectamente coherente tanto el hecho de que los miembros de los tribunales fueran elegidos por sorteo; cuanto la ausencia de operadores jurídicos, ya que se considera que cada ciudadano es capaz de actuar por sí mismo; como, en fin, la ausencia de recursos pues se considera asimismo que es el propio pueblo ateniense el que se está pronunciando 24 .

Pero, llegados a este punto, no procede seguir indagando en ese carácter presuntamente rudimentario y poco desarrollado desde un punto de vista técnico-jurídico del procedimiento seguido en el caso Sócrates, pues, hasta aquí, no hemos hecho suficiente hincapié en uno de los detalles de la descripción que efectuamos más arriba. Un detalle del que, como se verá, se seguiría una diferencia radical entre ambos procedimientos, pero que, sin embargo, se ha tergiversado de tal manera que se ha acabado considerando ese procedimiento radicalmente diferente de los nuestros como si no lo fuera.

\section{Un prejuicio no percibido individualista.}

Se ha señalado que lo "verdaderamente grave" del procedimiento seguido en el caso Sócrates era que el tribunal estuviera obligado a elegir entre una $\mathrm{u}$ otra de las penas propuestas y no pudiera condenar a ninguna otra pena que no fuese una de ellas ${ }^{25}$. Por nuestra parte, sin embargo y sin dejar de reconocer que esa circunstancia choca ciertamente con nuestra mentalidad jurídica, pensamos que lo verdaderamente grave es el hecho de que, una vez decidida la culpabilidad, el declarado culpable tuviera que proponer una pena alternativa a la propuesta por la parte acusadora: la llamada "antitímesis".

\footnotetext{
23 “Con esto resulta claro cuál es el ciudadano: llamamos, en efecto, ciudadano al que tiene derecho a participar en la función deliberativa o judicial de la ciudad, y llamamos ciudad, para decirlo en pocas palabras, una muchedumbre de tales ciudadanos suficiente para vivir con cierta autarquía.” ARISTÓTELES; Política, 1275a, Madrid, Instituto de Estudios Políticos, 1970, p. 69.

${ }^{24}$ SABINE, G.H.; Historia de la Teoría Política, cit. p. 20.

${ }^{25}$ CALONGE, J. quien, en la Apología cit., p. 144, nota 6, afirma: "Lo verdaderamente grave en este sistema es que el tribunal estaba obligado a elegir entre una u otra y no podía condenar a ninguna otra pena que no fuera una de ellas."
} 
Y en efecto, desde nuestro horizonte de praxis, resulta casi impensable semejante momento procesal pues, sin ir más lejos, con él se da por supuesto que no cabe error en la decisión de culpabilidad y, por tanto, que no cabe recurso alguno; algo inaudito desde nuestra perspectiva. Más aún y en el mismo sentido, se da también por sentado que el declarado culpable lo sería sin el menor atisbo de duda y ello hasta el punto de tener que reconocerse como tal proponiendo una contra pena. En otras palabras, ni se contempla la posibilidad de que el declarado culpable se considere a sí mismo inocente; algo asimismo inaudito desde nuestra perspectiva.

Así las cosas, no parece necesario insistir en que es justamente en este punto donde reside la diferencia radical entre ambos procedimientos. Y es que nuestros procedimientos $\mathrm{y}$, por tanto, nuestro horizonte de praxis, se sustentan no sólo en la separación de poderes, presunción de inocencia, principio de legalidad penal... sino, y sobre todo, en la existencia de un sujeto individual, un "yo", por así decirlo, con conciencia moral, con voluntad libre, con responsabilidad hasta el punto de que puede seguir considerándose inocente aun cuando haya sido declarado culpable.

Por el contrario, en el procedimiento utilizado en el caso Sócrates no se presupone tal "yo", tal sujeto moral responsable capaz de decidir autónomamente su culpabilidad o inocencia, sino que un sujeto colectivo decide la culpabilidad o inocencia, pero de modo tal que el declarado culpable reconoce, -si es que así puede hablarse-, que, en efecto, lo es y ello hasta el punto de proponer una contra-pena, una pena alternativa a la propuesta por la otra parte.

"Resulta casi impensable", "si es que así puede hablarse" decimos y decimos bien, pues desde nuestra mentalidad jurídica resulta difícil, si es que no imposible, comprender un procedimiento judicial en el que, primero, parece haber un "yo" pleno, en la medida en que se le considera capaz de defenderse por sí mismo, pero, después, una vez declarado culpable, dejaría de ser ese yo al adoptar la decisión del jurado como propia, asumiéndose como culpable sin que quepa la menor posibilidad, la más mínima duda de la corrección de esa decisión de culpabilidad, como lo demuestra tanto la consiguiente propuesta de la "antitímesis", -la pena alternativa a la propuesta por la otra parte-, cuanto la ausencia de recursos contra esa decisión a las que ya nos hemos referido más arriba.

Pero, a todo esto, bien podría objetarse que hasta aquí estamos hablando de "la diferencia radical entre el procedimiento utilizado en el caso Sócrates y nuestros procedimientos" sin haber hecho mención alguna al hecho de que, como es bien sabido, en el mundo occidental hay al menos dos concepciones 
procedimentales vigentes en nuestros días correspondientes a dos culturas jurídicas. De una parte, la que resulta del common law, donde prima el llamado adversarial procedure o procedimiento acusatorio en el que las partes tienen un gran protagonismo en la determinación de los hechos, adoptando el juez, en consecuencia, más bien una función de árbitro. De otra, la que se sigue de los sistemas de derecho civil, donde prima el procedimiento inquisitivo, adoptando el juez un papel directivo en la determinación de la verdad procesal de los hechos, toda vez que dirige la investigación y la práctica de la prueba. En otros términos, hasta aquí habríamos hablado con excesiva ligereza de "nuestros procedimientos" y "nuestra mentalidad jurídica", sin atender a esa distinción básica entre esas dos culturas jurídicas vigente en el mundo occidental.

Ahora bien, a esa posible objeción cabría responder aduciendo que, desde el punto de vista del procedimiento utilizado en el juicio contra Sócrates, no tiene sentido hacer esa subdivisión de "nuestros" procedimientos. Y es que "nuestros" procedimientos, el adversarial procedure y el inquisitivo, serían el mismo procedimiento en ese punto, dado que en ninguno de ellos cabe introducir un momento procesal en el que el declarado culpable tenga que reconocerse como tal y proponer una pena alternativa a la propuesta por la otra parte. Dicho con otras palabras, tanto el adversarial procedure del common law como el inquisitivo de los sistemas de derecho civil tienen la misma fundamentación, el mismo presupuesto individualista en cuanto que reconocen un individuo pleno capaz de sentirse inocente o culpable por sí mismo, con independencia de la decisión de un tribunal y, en ese sentido, cabe unificarlos, como hasta aquí hemos hecho, como "nuestros procedimientos", los procedimientos de una única cultura jurídica individualista con dos variantes: la del adversarial procedure y la del procedimiento inquisitivo; variantes que comparten el mismo presupuesto individualista. .

Más aún, y abundando en lo mismo, esa característica no individualista clave del procedimiento utilizado en el caso Sócrates resulta tan impensable, es tan difícil de expresar que, hasta donde sabemos, es normalmente obviada, si es que no tergiversada, tal y como se desprende, por ejemplo, de la siguiente cita de una monografía de 1990, titulada precisamente Socrates on Trial, situada en la órbita del common law y de la que, por lo demás, nos servimos en su momento para describir dicho procedimiento:

"We do not know the degree of legal obligation placed upon the defendant in such a trial procedure to offer a counter-penalty. One might think intuitively that it is unlikely the defendant would be legally constrained to offer an alternative, for it is difficult to imagine what the penalty for disobedience to such a legal constraint would be. After all, the defendant would already face 
a serious penalty (the one proposed by the prosecution) that he would automatically receive if he failed to offer an alternative."26

Como se puede leer, el texto vuelve sobre la propuesta de contra-pena, de pena alternativa a la propuesta por la otra parte y apunta a una cuestión en la que no habríamos reparado hasta el momento: si habría alguna previsión legal para el supuesto de que no se produjera dicha propuesta. En concreto, argumenta que es improbable que hubiera tal previsión por la dificultad de imaginar cuál sería y por el mero hecho de que, caso de no producirse la propuesta de contra-pena, se aplicaría la propuesta de la otra parte de modo que sería innecesaria cualquier previsión legal al respecto.

Ahora bien, este comentario es una buena muestra de lo difícil que resulta entender desde nuestra mentalidad jurídica individualista el procedimiento utilizado en el caso Sócrates precisamente porque se le escapa el punto crucial: no había previsión legal para el supuesto de no planteamiento de la contrapena porque esa posibilidad ni se contempla. Desde ese procedimiento, no cabe imaginar siquiera que el declarado culpable no se "reconozca" culpable, como se sigue de la ausencia de recursos contra la decisión del jurado y la propia institución de la "antitímesis", la propuesta de contrapena.

Más en concreto, al comentario transcrito se le escapa el punto crucial porque lo que hace es trasladar nuestros presupuestos, nuestro horizonte de praxis, al análisis de esa parte del procedimiento utilizado en el caso Sócrates. Y así, se da por supuesto un yo autónomo, un individuo, capaz de determinar por sí mismo si es culpable o inocente con independencia de la decisión del tribunal y, por tanto, capaz de negarse a plantear una contra-pena precisamente por considerarse inocente. En otros términos, el mero planteamiento de la posibilidad de un castigo para la no propuesta de contra-pena, presupone considerar que el declarado culpable no se tenga por tal; esto es, considerarle un yo pleno, moralmente responsable, un individuo capaz de decidir por sí mismo su culpabilidad o inocencia.

Prueba evidente de todo ello es que en ese comentario se utiliza la palabra "defendant", - esto es, “acusado"-, incluso cuando, en realidad, ya no habría tal "acusado", sino alguien que ya ha sido declarado

${ }^{26}$ BRICKHOUSE, TH. C. y SMITH, N.D.; Socrates on Trial cit., p. 217 y 218. 
"culpable"27; término que no aparece en la cita transcrita en lugar alguno cuando ciertamente debería hacerlo. Y es que, como vimos más arriba, en el procedimiento seguido en el caso Sócrates, la propuesta de contra-pena es realizada no por el "acusado", como supone literal y erróneamente el comentario transcrito, sino por el ya "declarado culpable".

Con todo lo cual, por cierto, este comentario no sólo serviría para poner de relieve la distancia que media entre nuestros procedimientos y el utilizado en el juicio contra Sócrates, sino también como un ejemplo perfecto de implementación de los prejuicios "no percibidos" a los que nos referimos en la introducción de este trabajo; esto es, de los prejuicios que "con su dominio nos vuelven sordos hacia la cosa desde la que nos habla la tradición" 28 . Y es que en lugar de escuchar lo que dice la tradición: "culpable", el comentario le hace decir "acusado" por mucho que ya haya dejado de serlo al haber sido declarado culpable.

Más aún, este comentario nos permitiría incluso aclarar la naturaleza de ese prejuicio no percibido que, ciertamente, habría de considerarse un prejuicio individualista en la medida en que, como hemos visto, da por supuesto en dicho procedimiento un yo pleno, un individuo autónomo y responsable capaz de decidir por sí mismo si es culpable o no, negándose, por tanto, en su caso, a asumir la culpabilidad decidida por el tribunal; esto es, no proponiendo una contra-pena. En otros términos y por volver a utilizar a Gadamer, el texto transcrito no sólo dice "acusado", cuando debiera decir "culpable", sino que, en último término, al decir "acusado" está diciendo, en realidad, “individuo".

No parece necesario insistir en todo lo que ello supone de sordera en relación con lo que nos dice la tradición en el caso Sócrates. Y es que, al incluir, -de forma no percibida, tal y como acabamos de ver-,

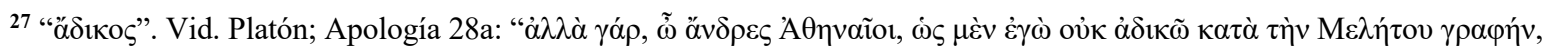

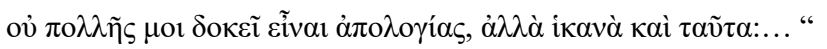

Esto es: "Pues bien, atenienses, me parece que no requiere mucha defensa demostrar que yo no soy culpable respecto a la acusación de Meleto, y que ya es suficiente lo que se ha dicho.”.PLATÓN; Apología cit. pp. 165.

28 "El que quiere comprender un texto tiene que estar en principio dispuesto a dejarse decir algo por él. Una conciencia formada hermenéuticamente tiene que mostrarse receptiva desde el principio para la alteridad del texto. Pero esta receptividad no presupone ni "neutralidad" frente a las cosas ni tampoco autocancelación, sino que incluye una matizada incorporación de las propias opiniones previas y prejuicios. Lo que importa es hacerse cargo de las propias anticipaciones, con el fin de que el texto mismo pueda presentarse en su alteridad y obtenga así la posibilidad de confrontar su verdad objetiva con las propias opiniones previas. (...) En consecuencia no se trata en modo alguno de asegurarse a sí mismo contra la tradición que hace oír su voz desde el texto, sino, por el contrario, de mantener alejado todo lo que pueda dificultar el comprenderla desde la cosa misma. Son los prejuicios no percibidos los que con su dominio nos vuelven sordos hacia la cosa desde la que nos habla la tradición.” GADAMER, H. G.; Verdad y método, Vol. I. cit. p. 335 y 336. 
el término “individuo" en el caso Sócrates, no sólo se está extrapolando un término posterior sino todo nuestro horizonte de praxis derivado precisamente de ese concepto.

Y en efecto, como es bien sabido el término "individuo" proviene del adjetivo latino "individuus, -a, um", habiendo sido utilizado por primera vez, hasta donde sabemos, por Cicerón en el sentido de átomo ${ }^{29}$ y "descubierto" siglos después, en plena modernidad ${ }^{30}$, de modo que no cabría ciertamente en la descripción del caso Sócrates.

Y tampoco es necesario insistir en que el individualismo es un fenómeno típicamente moderno de modo que tampoco cabría en dicha descripción. Y es que hay acuerdo unánime al respecto de la modernidad del individualismo como se sigue, por todas, de las dos siguientes citas:

"En efecto, el individualismo, la consideración del ser humano como un individuo que desarrolla libremente su vida en sociedad, que no es parte de una casta o un estamento, sino un átomo independiente, que se asocia con otros individuos para formar grupos sociales $\mathrm{y}$ comunidades, es una idea específicamente moderna. "31

"Lo mejor será partir de la propia palabra individualismo, que empleamos muy habitualmente hoy pero que apareció a comienzos del siglo XIX (hay testimonios a partir de $1826) " 32$.

Más aún, tampoco parece necesario recordar que el concepto de individuo es "esencial" para el liberalismo ${ }^{33}$, de modo que ese comentario acaba introduciendo también en la tradición en la que se seguía ese procedimiento, todo el liberalismo que, como también es bien sabido, se considera de forma unánime plenamente moderno:

"Como corriente política y tradición intelectual, como un movimiento identificable en la teoría y en la práctica, el liberalismo no es anterior al siglo XVII. De hecho, el epíteto "liberal",

\footnotetext{
${ }^{29}$ Según EUCKEN R.; Geschichte der philosophischen Terminologie. Hildesheim, Georg Olms Verlagsbuchhandlung 1964, p. 52. Cfr. FERRATER MORA, J.; Diccionario de Filosofía Vol. II Madrid Alianza, ,1983, p. 41.

${ }^{30}$ Por utilizar el título del libro DÜLMEN, R. van; El descubrimiento del individuo 1500-1800. Madrid, Siglo XXI, 2016.

${ }^{31}$ LÓPEZ HERNÁNDEZ, J.; La teoría del Estado en sus fuentes: de Maquiavelo a Marx. Madrid, Tecnos, 2020, p. 50.

${ }^{32}$ MANENT, P.; Curso de Filosofía Política, Buenos Aires, FCE. 2003, p. 141.

${ }^{33}$ MULHALL St. y SWIFT, A.; El individuo frente a la comunidad: El debate entre liberales y comunitaristas, Madrid Temas de Hoy, 1996, p. 44.
} 
aplicado a un movimiento político no se usa por primera vez hasta el siglo XIX, cuando en 1812, lo adopta el partido español de los "liberales". 34

Así las cosas y en conclusión, ya habríamos identificado la causa de que se haya malinterpretado lo que la tradición nos dice en relación con el caso Sócrates: la implementación de un prejuicio no percibido que, en lugar de escucharla y oír lo que dice: “culpable", oye "acusado" y, en último término, "individuo", introduciendo así un término anacrónico, típico de la modernidad, y con él toda la filosofía que en él se sustenta: el individualismo y el liberalismo típicos, ciertamente, de nuestro horizonte de praxis.

A todo esto, se dirá que estamos yendo demasiado rápido y que estamos derivando conclusiones definitivas sobre un presunto prejuicio individualista no percibido aplicado al análisis del caso Sócrates a partir de un solo comentario. Un solo comentario que, por mucho que sea relativamente reciente, por mucho esté formulado en la lengua franca de nuestro tiempo: el inglés, y provenga de una universidad del mayor prestigio, ciertamente no sería prueba suficiente para sustentar tales conclusiones.

Ahora bien, a esa presunta objeción podría contestarse aduciendo otro comentario al respecto, aún más reciente que el anterior, -2009 y 1990, respectivamente-, expresado asimismo en la lengua franca de nuestros días y proveniente también de una universidad del máximo prestigio. Un comentario de un autor también del ámbito del common law y del que asimismo nos servimos más arriba para describir el procedimiento utilizado en el caso Sócrates. Un comentario que reza como sigue:

"For the kind of trial Socrates underwent (an agôn timetôs) was divided procedurally into two parts. In the first, the issue was the defendant's guilt or innocence. In the second, if the majority voted 'guilty', the issue was the nature of the convicted man's penalty (timê), and prosecutor and defendant again spoke to that." 35

No parece preciso repetir las consideraciones que hicimos más arriba a propósito de cómo el primer comentario no escuchaba lo que la tradición nos dice en el caso Sócrates, y cómo, en lugar de "culpable", oía "acusado", y, en último término, "individuo" pues, como se sigue inmediatamente, este último comentario incurre en la misma tergiversación, extrapolando de igual modo nuestra propia mentalidad

\footnotetext{
${ }^{34}$ GRAY, J.; Liberalismo, Madrid, Alianza,1994, p. 9.

${ }^{35}$ CARTLEDGE, P.; Ancient Greek Political Thought in Practice, cit., p. 89.
} 
jurídica, nuestro propio horizonte de praxis. Y en efecto, al referirse a la segunda parte del procedimiento, una vez declarado el acusado "culpable", sigue hablando de acusado, "defendant":

"....and prosecutor and defendant again spoke to that."

A todo esto, quizás se reproche que sólo utilizamos ejemplos del ámbito del common law, en inglés, y que, por mucho que sea la lengua franca en nuestros días, ya que hablamos de "nuestro horizonte de praxis" en el sentido que especificamos más arriba, deberíamos aportar también alguna prueba al respecto de lo anterior en "nuestra" lengua; esto es, deberíamos utilizar también alguna cita de algún autor español contemporáneo en el mismo sentido.

Algo que, ciertamente, no plantea excesivos problemas, -lo cual, por cierto, viene a corroborar la corrección de las conclusiones anteriores-, y es que la implementación de ese prejuicio individualista no percibido aparece también entre nosotros, los hispano hablantes, -dentro de la concepción de derecho civil, pues-, tal y como se desprende de la siguiente cita de uno de los más importantes pensadores españoles contemporáneos:

“El proceso de Sócrates se desencadenó por razones políticas. Algunos de sus discípulos estuvieron vinculados a la tiranía oligárquica y las autoridades democráticas creyeron oportuno alejarlo de la pólis. Se le acusó de pervertir a los jóvenes, de defender el ateísmo y, paradójicamente, de introducir nuevos dioses. Se pidió la pena de muerte porque, según el derecho ateniense, el acusado podía optar por un castigo alternativo como el exilio. Pero Sócrates expresó que o bien era culpable y merecía la muerte, o bien no lo era y entonces debían ser reconocidos sus servicios a la sociedad. Rechazó la posibilidad del exilio y hasta ironizó sobre la idoneidad de sus jueces. Fue condenado a beber una copa de cicuta, aceptó la sentencia con gran dignidad y murió sin sobresaltos. " 36

Y, en efecto, en esta cita, -al margen de que se liga de manera inconsistente la petición de pena de muerte con la posibilidad de un castigo alternativo, sin que, por razones de espacio, proceda abundar en ello-, también se aprecia la aplicación del mismo prejuicio no percibido individualista a la hora de describir el procedimiento utilizado en el caso Sócrates. Al igual que en las dos citas en inglés anteriores, se hace decir a la tradición "acusado" y, en último término, "individuo", cuando, en realidad, dice "declarado culpable":

${ }^{36}$ SAVATER, F.; La aventura de pensar. Barcelona, Random House Mondadori, 2008, p. 15. 
"Se pidió la pena de muerte porque, según el derecho ateniense, el acusado podía optar por un castigo alternativo como el exilio."

\section{A modo de conclusión.}

Así las cosas, dada la procedencia y actualidad de todas estas citas, quedarían más que validadas las conclusiones a las que llegábamos más arriba en relación con la implementación de un prejuicio no percibido individualista a la hora de describir el procedimiento seguido en el caso Sócrates. Un procedimiento que estaríamos tergiversando por completo, -vía extrapolación de nuestro horizonte de praxis individualista-, y al que, en consecuencia, desde lo visto hasta aquí, solo podríamos caracterizar $a$ contrario como "no individualista".

Por lo demás, ni que decir tiene que esas conclusiones vienen reforzadas por las diferentes maneras de desatender, de desoír lo que dice la tradición en el caso Sócrates a las que nos hemos referido más arriba. Maneras en las que ese procedimiento era bien obviado y, por tanto, absorbido implícitamente; bien asimilado al nuestro individualista y, por tanto, absorbido explícitamente; bien descrito sin enfatizar las diferencias o reduciéndolas a mera expresión de un carácter "rudimentario" o "poco desarrollado técnicamente", y, por tanto, absorbiéndolo como un estadio previo de nuestra cultura jurídica. Diferentes maneras de no escuchar la tradición no individualista del caso Sócrates a las que, obviamente, subyace de modo implícito ese prejuicio no percibido individualista, -el individualismo, en último término-, que tan claramente ha aparecido en las tres citas recién analizadas.

Pero a todo esto, no sólo habríamos identificado la causa principal de la falta de atención al procedimiento utilizado en el caso Sócrates: la aplicación de un prejuicio individualista no percibido, sino que, a la vista de lo anterior, también podríamos concluir, razonablemente, que es muy probable que ese prejuicio no percibido se haya aplicado en otros supuestos, en otros "casos".

Y así, por ejemplo y sin ir más lejos, cabría pensar que también se habría aplicado en el, por así llamarlo, “caso Aristóteles", toda vez que, como hemos señalado en otro lugar ${ }^{37}$, términos aristotélicos claves $^{38}$ han sido traducidos utilizando precisamente el término "individuo". Más aún, cabría pensar que el

\footnotetext{
${ }^{37}$ PRADA, A. de; Hacia una síntesis entre el comunitarismo y el liberalismo: La ciudadanía glocal. Anales de la Cátedra Francisco Suárez, n. 55, Granada 2021, p. 509-533

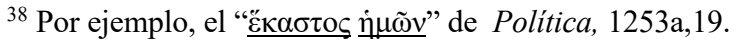


análisis del "caso Aristóteles" no solo corroboraría las conclusiones aquí alcanzadas, sino que quizás permitiría también precisar el momento concreto en el que históricamente empezó a implementarse el prejuicio no percibido individualista que hemos detectado en el "caso Sócrates". Ahora bien, ampliar el análisis realizado aquí a ese presunto "caso Aristóteles" es algo que, ciertamente, va más allá de los límites impuestos a estas líneas. 


\section{Bibliografía utilizada.}

ABBAGNANO, N.; Historia de la Filosofía. Vol. I, Barcelona Montaner y Simón, 1973, 598 pp.

ARISTÓTELES; Política. Madrid, Instituto de Estudios Políticos, 1970, 281 pp.

BRICKHOUSE, TH. C. y SMITH, N. D.; Socrates on Trial. Oxford, Clarendon,1990, 337 pp.

CALONGE, J.; Introducción y notas de la Apología de Sócrates en PLATÓN; Diálogos I, Madrid Gredos, 1981, pp.140-186.

CARTLEDGE, P.; Ancient Greek Political Thought in Practice. Cambridge, Cambridge University Press, 2009, 169 pp.

COOPER, D. E.; Filosofías del Mundo. Madrid, Cátedra, 2007, 727 pp.

DAL MASCHIO, E. A.; Platón. Barcelona, Batiscafo, 2015, 140 pp.

DÜLMEN, R. van; El descubrimiento del individuo 1500-1800 Madrid, Siglo XXI, 2016, 174 pp.

EUCKEN R.; Geschichte der philosophischen Terminologie. Hildesheim, Georg Olms Verlagsbuchhandlung, 1964, 230 pp.

FASSÓ G.; Historia de la Filosofía del Derecho. Vol. I, Madrid, Pirámide, 1966, 254 pp.

FERRATER MORA, J.; Diccionario de Filosofía. Vol. II. Madrid Alianza,1983, pp. 385-789.

GADAMER, H. G.; Wahrheit und Methode en Gesammelte Werke tomo 1, München, Mohr Siebeck, 1990, 495 pp.

GADAMER, H. G.; Verdad y método, Vol. I. Salamanca, Sígueme, 1996, 675 pp.

GARCÍA GUAL, C.; “Acerca de El proceso de Sócrates de Gregorio Luri” en LURI MEDRANO, G.: El proceso de Sócrates., Madrid, Trotta, 1998, pp. 9-12.

GARCÍA GUAL, C.; "Los Sofistas y Sócrates” en VVAA; Historia de la ética. Barcelona, Crítica, 1987, pp. 35-79.

GRAY, J.; Liberalismo. Madrid, Alianza,1994, 158 pp.

GUTHRIE E, W.K.C.; Historia de la Filosofía Griega. Vol. III., Madrid, Gredos, 1988, 513 pp.

HERMAN HANSEN, M.: El juicio de Sócrates desde el punto de vista ateniense. Universitas Philosophica 67, año 33, Bogotá, Colombia, julio-diciembre 2016, pp. 17-52. doi:10.11144/Javeriana.uph33-67.jsv

KNAUSS, B.; LA POLIS. Individuo y estado en la Grecia Antigua. Madrid, Aguilar, 1979, 312 pp.

LÓPEZ HERNÁNDEZ, J.; Historia de la filosofía del derecho clásica y moderna. Valencia, Tirant lo Blanch,1998, 477 pp. LÓPEZ HERNÁNDEZ, J.; La teoría del Estado en sus fuentes: de Maquiavelo a Marx. Madrid, Tecnos, 2020, 540 pp.

LURI MEDRANO, G.; El proceso de Sócrates. Madrid, Trotta, 1998,150 pp.

LLEDÓ E.; “Introducción general” en PLATÓN: Diálogos I. Madrid, Gredos, 1981, pp.7-136.

MACINTYRE, A.; Historia de la Ética. Barcelona, Paidós Studio, 1988, 259 pp.

MANENT, P.; Curso de Filosofía Política. Buenos Aires, FCE. 2003, 267 pp. 
MULHALL St. y SWIFT, A.; El individuo frente a la comunidad: El debate entre liberales y comunitaristas, Madrid, Temas de Hoy, 1996, 463 pp.

PARDO, J.L.; La regla del juego. Barcelona, Galaxia Gutenberg, 2004, 685 pp.

PLATÓN; Apología de Sócrates. en Diálogos, I, Madrid Gredos, 1981, pp. 148-186.

PLATÓN; Protágoras. en Diálogos, I, Madrid Gredos, 1981, pp. 487-589.

PRADA, A. de: Soberanía popular, poder judicial y jurado en el sistema jurídico español: Algunas consideraciones. Revista de la Facultad de Derecho de la Universidad Complutense, n. 93, Madrid 2000, pp. 221-233.

PRADA, A. de; Tomando a Sócrates en serio: De la ciudadanía antigua a la ciudadanía glocal. Anales de la Cátedra Francisco Suárez, n. 54, Granada 2020, p. 53-70.

PRADA, A. de; Hacia una síntesis entre el comunitarismo y el liberalismo: La ciudadanía glocal. Anales de la Cátedra Francisco Suárez, n. 55, Granada 2021, p. 509-533.

REALE, G. y ANTISERI, D.; Historia del pensamiento filosófico y científico. Tomo I Antigüedad y Edad Media. Barcelona, Herder, 1995, 613 pp.

RIVAS PALÁ, P.; Justicia, Comunidad, Obediencia. El pensamiento de Sócrates ante la Ley. Pamplona, Eunsa, 1996, 378 pp.

RODRÍGUEZ PANIAGUA, J.M.; Historia del pensamiento jurídico. Vol. I De Heráclito a la Revolución Francesa., Servicio Publicaciones de la Facultad de Derecho, Madrid, Universidad Complutense, 1996, 318 pp.

RUSSELL, B.; Historia de la Filosofía, Madrid, RBA, 2009, 892 pp.

SABINE, G. H.; Historia de la Teoría Política, México FCE 1972, 675 pp.

SANCÉN RODRÍGUEZ, J. y ANCHONDO PAVÓN, S.; Filosofía, Ciudad de México SEP, 2016, 193 pp.

SAVATER, F.; La aventura de pensar. Barcelona, Random House Mondadori, 2008, 340 pp.

SEVERINO, E.; La filosofía antigua. Barcelona, Ariel, 1986, 224 pp.

STONE, I. F.: El juicio de Sócrates. Madrid, Mondadori, 1988. 294 pp.

STÖRIG, H. J.; Historia universal de la Filosofía. Madrid, Tecnos, 1995, 808 pp.

TRUYOL y SERRA, A.; Historia de la Filosofía del Derecho y del Estado, Vol. 1. Madrid, Alianza Universidad, 1982, 476 pp.

VERDROSS, A.; La filosofía del derecho del mundo occidental. México, UNAM 1983,433 pp. 